IZA DP No. 9110

Saving Face and Group Identity

Tor Eriksson

Lei Mao

Marie Claire Villeval

June 2015 


\title{
Saving Face and Group Identity
}

\author{
Tor Eriksson \\ Aarhus University \\ Lei Mao \\ Central University of Finance and Economics \\ Marie Claire Villeval \\ Université de Lyon, CNRS, GATE \\ and IZA

\section{Discussion Paper No. 9110 \\ June 2015}

IZA
P.O. Box 7240
53072 Bonn
Germany

Phone: +49-228-3894-0

Fax: +49-228-3894-180

E-mail: iza@iza.org

Any opinions expressed here are those of the author(s) and not those of IZA. Research published in this series may include views on policy, but the institute itself takes no institutional policy positions. The IZA research network is committed to the IZA Guiding Principles of Research Integrity.

The Institute for the Study of Labor (IZA) in Bonn is a local and virtual international research center and a place of communication between science, politics and business. IZA is an independent nonprofit organization supported by Deutsche Post Foundation. The center is associated with the University of Bonn and offers a stimulating research environment through its international network, workshops and conferences, data service, project support, research visits and doctoral program. IZA engages in (i) original and internationally competitive research in all fields of labor economics, (ii) development of policy concepts, and (iii) dissemination of research results and concepts to the interested public.

IZA Discussion Papers often represent preliminary work and are circulated to encourage discussion. Citation of such a paper should account for its provisional character. A revised version may be available directly from the author. 


\section{ABSTRACT}

\section{Saving Face and Group Identity*}

Are people willing to sacrifice resources to save one's and others' face? In a laboratory experiment, we study whether individuals forego resources to avoid the public exposure of the least performer in their group. We show that a majority of individuals are willing to pay to preserve not only their self- but also other group members' image. This behavior is frequent even in the absence of group identity. When group identity is more salient, individuals help regardless of whether the least performer is an in-group or an out-group. This suggests that saving others' face is a strong social norm.

JEL Classification: C92, D03, M52, Z13

Keywords: saving face, social image, pro-social behavior, group identity, experiment

Corresponding author:

Marie Claire Villeval

CNRS, GATE Lyon St Etienne

93, Chemin des Mouilles

F-69130, Ecully

France

E-mail: villeval@gate.cnrs.fr

\footnotetext{
${ }^{*}$ We are grateful to participants at the Economic Science Association in New-York, the $3{ }^{\text {rd }}$ Annual Xiamen University International Workshop on Experimental Economics, the ASFEE conference in Montpellier, the workshop on Cooperation, cultural aspects and norms in Jerusalem, and seminar participants at GATE for valuable comments on an earlier version of this paper. We also address special thanks to F. Galeotti and D. Houser for very useful comments. We thank S. Ferriol, R. Cautain and $\mathrm{Q}$. Thévenet for programming this experiment and $\mathrm{T}$. He and $\mathrm{Y}$. Chen for excellent research assistance. This research program has been supported by a grant from the French National Research Agency (ANR, EMCO program, HEIDI grant) and was performed within the framework of the LABEX CORTEX (ANR-11-LABX-0042) of Université de Lyon, within the program "Investissements d'Avenir" (ANR-11-IDEX-007) operated by the French National Research Agency (ANR).
} 


\section{INTRODUCTION}

The concern for one's and other's image is crucial for diplomacy, informal contract enforcement, maintenance of business networks, good employment relationships, successful bargaining situations (Ting-Toomey, 2005). Yet, individuals or organizations' image may be threatened by the development of practices like the dissemination of performance ratings that praise the best performers but may also shame the least performers. Examples include school quality rankings, citation indices and rankings in academia, ranking of sellers on on-line purchasing websites, employee performance evaluations in organizations. ${ }^{1}$ While rankings may motivate some individuals to outperform others, they may also generate losses of utility in terms of image. Indeed, individuals may lose face and be less willing to identify themselves with their employer.

If people make efforts to protect their own image, are they also willing to sacrifice monetary resources to save other's face? Social psychologists have shown how preserving image is important for humans in society (Spencer et al., 2001; Baumeister et al., 2005; Mruk, 2006). Sociologists have studied how self-esteem and considerateness for others lead people to preserve self- and others' face in social encounters. Goffman has defined face as "an image of self delineated in terms of approved social attributes" (2005, p.5), and shown that face-saving practices are a condition for social interactions. In contrast, economists have not widely investigated the importance of face-saving for the self and others. ${ }^{2}$ This study aims at contributing to understand face saving by combining the economic analysis of image and social preferences. Recent theories (Benabou and Tirole, 2006; Koszegi, 2006) and empirical tests of image concern (Johansson-Stenman and Svedsater, 2012; Johansson-Stenman and Martinsson, 2005; Alpizar et al., 2008; Ariely et al., 2009; Lacera and Macis, 2010; Cappelen et al., 2012) demonstrate that individuals care about how others perceive their actions. People are motivated by what others think about them (Ellingsen and Johannesson, 2007, 2008a; Eriksson and Villeval,

\footnotetext{
${ }^{1}$ Many firms struggle to find a well-functioning performance evaluation system. Recently, well-known companies have abolished their annual performance review (Adobe) or moved from a rigid, forced ranking approach to systems that are more flexible (Microsoft, Yahoo). One aspect that is not recognized in the literature is the loss of face (selfas well as others' image) associated with performance evaluations in which individuals' ranks are publicly exposed. ${ }^{2}$ An exception is Hugh-Johns and Reinstein (2010) who study loss of face as the disutility for common-knowledge of rejection. The fear of losing face leads to inefficiencies in markets because it leads to fewer offers.
} 
2011). These studies do not, however, directly examine the value for individuals to maintain selfand others' face.

In this paper, we study experimentally whether people sacrifice monetary resources to avoid being publicly exposed - i.e. to save face - when exposure signals that the individual's performance is the lowest compared to others. Another originality is analyzing how large is the share of individuals who accept incurring costs to save the face of others without reaping any personal material benefit from this action. Testing face saving would be very difficult by means of survey or registry data. Therefore, we have designed a laboratory experiment that we tested in China from where the concept of face (mien-tzu) originates (Ho, 1976). ${ }^{3}$ In the Baseline treatment subjects are matched in triads and have to perform a real-effort task for a fixed payment. In one part of the treatment, those whose performance is lowest in their triad are singled out and briefly publicly exposed. Although the equilibrium is not exerting any effort, public exposure may be perceived as signaling a lower status. It is thus susceptible to shame individuals. ${ }^{4}$ It can however be avoided if at least two triad members are willing to pay a fee. This one-shot decision allows us to measure the likelihood of sacrificing resources to save one's and others' image.

One contribution of this paper is showing that most individuals strive to save face and are willing to pay to avoid public exposure. Moreover, more than half of the subjects sacrifice some of their material interest to avoid others' exposure. Such a behavior can be related to empathy, altruism (Andreoni and Miller, 2002) and norm enforcement to maintain the integrity of a society (Fehr and Fischbacher, 2003) in the domain of image. A major contribution is showing that altruistic behavior extends beyond the pecuniary realm and includes taking actions that benefit the social standing of others.

Then, we investigate whether the willingness to avoid others' exposure is sensitive to the

\footnotetext{
${ }^{3}$ Face is a key dimension in the Confucian culture to orchestrate social interactions ( $\mathrm{Hu}, 1944$; Redding and $\mathrm{Ng}$, 1982; Yang, 1989; Qi, 2011). The concern of Chinese for face results from a socialization process using shaming techniques to inculcate strong sensitivity to group belonging and others' opinion (Redding and Ng, 2002). The concern for others' image is called "giving face" in Chinese.

${ }^{4}$ We kept the procedure as soft as possible to avoid creating too much embarrassment. In psychology, Smith et al. (2002) have shown that shame has two core features: its links with public exposure and with negative self-evaluation.
} 
saliency of group identity. Indeed, the link between identity, on the one hand, and face, on the other hand, has been little explored in the literature (Spencer-Oatey, 2007). Therefore, we study whether individuals are more willing to pay for saving the face of in-groups than the face of out-groups. By addressing these questions, we contribute to the recent economic literature on group identity (Akerlof and Kranton, 2000; Bowles and Gintis, 2004; Fershtman and Gneezy, 2001; Bernhard et al., 2006; Charness et al., 2007; Chen and Li, 2009; Hargreaves Heap and Zizzo, 2009; Zizzo, 2011; Goette et al., 2012; Masella et al., 2014).

While in the Baseline triad membership induces a minimal group identity, in other treatments we manipulate the social distance in several directions, either increasing it by withdrawing the notion of triads or adding a "label identity" to triad members, based on the methodology developed in social psychology by Tajfel et al. (1971) and Tajfel and Turner (1979). In the Random treatment we no longer mention the notion of triad and individuals are matched with two randomly rematched participants at the beginning of each new part. In one part individuals can still pay for avoiding the exposure of the least performer among themselves and two other co-participants but in contrast with the Baseline these co-participants are strangers. In the Homogenous treatment, the triad members share the same label (Klee or Kandinsky, as explained below), while in the Heterogeneous treatment labels are mixed within each triad. When people hold the same label the social distance should be reduced, while it should increase when they do not. These treatments allow us to identify whether there is a conflict between a general norm of saving others' face and another norm according to which one should save the face of in-groups but not of out-groups. We can thus measure whether image management is affected by social distance or if it is mainly driven by a general moral norm independent of group membership.

A third important finding is showing that strengthening social identity or creating heterogeneous groups makes no significant difference as compared to the Baseline in the choice to save one's and other's face. People are willing to help out-group as much as in-group members. Significantly less people are sacrificing resources to save others' face when there is no group formation (Random treatment); but even in this context, more than one third of the individuals 
are willing to help to save strangers' face. This suggests that preserving other's face is a strong norm that is robust to a more individualistic environment.

Finally, we examine how public exposure affect effort. Ex ante, the threat on image may either crowd-out intrinsic motivation or boost performance to avoid exposure. For example taxpayers are more compliant when detection of fraud leads to the public display of the evaders' pictures (Coricelli et al., 2010). Ex post, the shaming effect of public exposure may also either crowd-in intrinsic motivation if individuals work harder to restore their image, or crowd-out motivation because image has been altered (Coricelli et al., 2014). We carry out performance comparisons between each treatment and a Control treatment in which subjects do not receive any social information and have no risk of public exposure. We fail to find evidence of an ex ante effect of the threat of exposure on performance, but we establish some evidence that having been exposed tends to crowd-out the intrinsic motivation to perform in the future. In contrast to Masella et al. (2014) who found that identity modulates the impact of incentives schemes on performance we find little effect of group identity on the impact of exposure on performance.

Overall, these findings have implications for the importance of protecting people's face and for employers to avoid modes of evaluation or feedback policies that may threaten the social image of individuals in the organization or the society.

In the remainder of the paper, Section 2 summarizes the related literature. Section 3 describes the experimental design and procedures and presents our behavioral conjectures. Section 4 reports our findings and Section 5 discusses the results and concludes.

\section{RELATED LITERATURE}

Our paper contributes to three literatures. One are studies of identification and audience effects. These studies have shown that prosocial choices are affected by identification (Bohnet and Frey, 1999; Charness and Gneezy, 2008) and anticipated verbal feedback (Ellingsen and Johannesson, 2008b), and that punishment in public promotes norm obedience (Xiao and Houser, 2011). While these studies ensure the anonymity of interactions, our design exposes singled-out individuals to an audience. The presence of a non-anonymous audience has been shown to increase prosociality 
(Ariely et al., 2009), tax compliance (Coricelli et al., 2010), coordination on the audience's preferred outcome in the battle-of-sexes game and defection in the prisoner's dilemma (Charness et al., 2007), and inflation of stated self-assessment (Ewers and Zimmerman, 2015). These studies point to the importance of social approval. ${ }^{5}$ Our analysis complements them by examining the willingness to pay to preserve image.

Second, we contribute to the literature on group identity. In naturally occurring groups, in-group favoritism has been observed in norm enforcement (Bernhard et al. (2006) because of social ties (Goette et al., 2006, 2012a). Discrimination of the opposite group has been identified both in dictator games (Ben-Ner et al., 2009; Abbink and Harris, 2012) and competition games (Goette et al., 2012b; Kato and Shu, 2013). Using the minimal group paradigm, studies have shown that group identity strengthens prosocial behavior (Chen and $\mathrm{Li}, 2009)$ while people act more selfishly when opposed to out-groups (Kollock, 1998; Charness et al., 2007; Zizzo, 2011), and that trust decreases with group membership because of discrimination against out-groups (Hargreaves Heap and Zizzo, 2009). ${ }^{6}$ Our contribution is a study of whether face saving is a general norm or a discriminatory process conditional on the social distance with the victim.

Third, we contribute to the literature on the incentive effects of social status. Status can be conferred by public recognition, performance feedback and ranking. These measures act as incentives on effort (Kosfeld and Neckerman, 2011; Kuhnen and Tymula, 2012; Tran and Zeckhauser, 2012; Bradler et al., 2013) and cooperation (Eckel et al., 2010), although their effect is not unequivocal (Barankay, 2012; Charness et al., 2014). By singling-out the least productive individuals we can examine the impact of anticipated decreased status on further performance. ${ }^{7}$

\footnotetext{
${ }^{5}$ There is also a literature on the willingness-to-pay for privacy, showing that people are less willing to disclose personal information when information is more sensitive (Feri et al., 2013), or in the absence of economic advantage associated with disclosure (Beresford et al., 2012). While we are also concerned with the privacy of sensitive data, we differ from this literature in which disclosure is voluntary.

${ }^{6}$ This is not systematic, however, as the impact of group identity on behavior is conditional on the saliency of identity (Eckel and Grossman, 2005), the procedure used to generate identity (Guala et al., 2013), the group size (Harris et al., 2009), the mode of group formation (Herbst et al., 2012), the existence of inter-group conflicts (Chakravarty and Fonseca, 2011), and culture (Buchan et al., 2009).

${ }^{7}$ Galeotti and Zizzo (2014) also analyze singling-out in a trust game in which it is random or it results from others' preferences. Solo identity reduces trustworthiness and majority group members discriminate singled-out subjects
} 


\section{EXPERIMENTAL DESIGN AND PROCEDURES}

\subsection{Treatments}

The experiment consists of four main treatments: a Baseline treatment and three treatments in which we either remove or increase the saliency of group identity. A final treatment has been added to control for learning and the evolution of performance over time.

\section{Baseline treatment}

At the beginning of a session, we randomly form triads that remain fixed for the entire session. Each session consists of four parts (see instructions in Appendix). In each part, subjects have to perform a simple task during four minutes. More precisely, they have to pick an apple on the screen and move it into a collecting basket located at the bottom of the screen. As soon as an apple enters the basket, a new apple appears at a random spot on the screen. Each apple moved into the basket earns one point. A counter displays the current score. The task does not require any skills and the score constitutes a proxy of the level of effort. ${ }^{8}$ Participants receive a fixed wage of 100 ECU (Yuan 10, about U.S. \$1.65) in each of the four parts.

Parts differ from each other in terms of feedback and risk of exposure. At the end of part 1, subjects learn their own score. At the end of parts 2 and 3, they are also informed about the score and the rank of each member in their triad, with rank 1 assigned to the best performer and rank 3 to the least performer. In case of ties, ranks are assigned randomly between the ties. At the end of part 3, subjects with rank 3 are requested to move to the front of the room one by one before coming back to their seat. These rules are made common information in the instructions. ${ }^{9}$ Public exposure can, however, be waived if at least two triad members choose to pay to avoid the public exposure of the member with rank 3. In this case, $10 \mathrm{ECU}$ are deducted from the payoff of those who chose to pay. If less than two triad members chose to pay the fee, the member with rank 3 is publicly exposed and no deduction is made. Each member is informed about which triad member offered to pay and who did not. Finally, part 4 replicates the features of part 2: after performing

\footnotetext{
${ }^{8}$ Using a task in which a low performance would signal low cognitive ability would have generated more embarrassment in case of exposure, which we wanted to avoid for ethical reasons. Thus, the intensity of shame due to public exposure in a professional or educational environment is probably underestimated in our experiment.

9 We acknowledge that the impact of public exposure cannot be disentangled from that of lifting anonymity.
} 
the task again during four minutes, subjects are informed on the score and rank of each triad member, with no risk of exposure.

We elicited the emotional state of the subjects by using a self-reported emotion survey as in Hopfensitz and Reuben (2009). Although we are chiefly interested in the feelings of shame and happiness, at several steps ${ }^{10}$ subjects report the intensity of ten emotions that they may experience at this precise moment (anger, contempt, shame, envy, sadness, happiness, guilt, gratefulness, fear, relief) on a Likert-type scale from 1 to 7 (the highest possible intensity).

\section{Homogeneous/Heterogeneous Label treatments}

In the Baseline treatment, belonging to a triad may generate a group identity. To explore whether the willingness to save others' face is affected by the social distance between members, we have designed two conditions of a treatment in which we add another group affiliation that is congruent or not with the triad membership. In the homogeneous label condition (hereafter, "Homogenous treatment"), triads are formed of subjects who received the same label. Thus, group identity deriving from triad membership is reinforced and social distance is further reduced. In the heterogeneous label condition (hereafter, "Heterogeneous treatment"), triads are formed of subjects who received different labels. Thus, compared to the Baseline, social distance may be increased in the triad if the least performer has a different label than the other triad members.

Labels are assigned in a preliminary part for the whole session, using a procedure inspired by the minimal group paradigm of Tajfel (1971). This part consists of two stages. In the first stage, subjects are randomly assigned to one of two groups of similar size, named the Kandinsky group and the Klee group, respectively. In the second stage, they engage in a recognition task. They review five pairs of paintings created by Klee and Kandinsky respectively, during 20 seconds each. The screen indicates which artist painted each painting. Next, they review two anonymous paintings successively and they are requested to report which artist painted each of them (Klee or Kandinsky). Each correct answer pays 50 ECU. Before entering responses, subjects can communicate with their in-groups during three minutes by means of a chat box.

10 That is at the beginning of the session, after receiving feedback at the end of part 1 , at the end of part 2, during part 3 after choosing to pay to avoid public exposure, after the exposure stage, and at the end of part 4. 
They receive a feedback on the correctness of answers at the end of the session.

Once labels have been assigned, the rest of the experiment is similar to the Baseline except that individuals are aware of the composition of their triad in terms of group identity and that publicly exposed individuals have to indicate aloud their label.

\section{Random treatment}

In the Random treatment, subjects are not working in a triad. In each part starting after part 1, we compare their performance with the performance of two other randomly selected subjects in the same session, and we rematch players randomly in each new part. Subjects are asked whether

they are willing to pay for avoiding the exposure of the least performer among the three subjects who mare matched together in part 3, knowing that these subjects are likely not the same as in the previous part. Therefore, the social distance with the potentially exposed least performer is higher compared to the Baseline. With these manipulations, we can measure whether the willingness to pay to save face is dependent on social distance.

\section{Control treatment}

Comparisons of performance in parts 1 and 2 reveal whether individuals adjust effort when they anticipate being informed about their relative performance. Comparing performance in parts 2 and 3 indicates whether the perspective of being publicly exposed boosts effort or crowds-out intrinsic motivation. Finally, comparing performance in parts 3 and 4 measures whether exposure has a detrimental effect on effort in part 4. However, this interpretation is conditional on people not learning the task over time. To control for this, we have run a control treatment in which the only information participants get at the end of each part is their own score. Subjects never receive any social information and there is no risk of exposure.

\section{Belief elicitation}

Requiring that two out of three triad members pay the fee to avoid exposure may give rise to a coordination problem. We have therefore elicited the participants' beliefs about the number of other triad members who will choose to pay the fee $(0,1$ or 2$)$. This question was asked just after the individuals made their decision in part 3 and it was not mentioned in the instructions to avoid 
focusing attention on the coordination issue. A correct prediction paid $50 \mathrm{ECU}$. This question has been introduced after the first eight sessions.

\subsection{Procedures}

The experiment was conducted at the experimental laboratory of Beijing Normal University, Beijing, China. Posters inviting students to participate were posted on online campus forums of BNU and Beijing University of Posts and Telecommunications and flyers were distributed on the campuses. In total 420 students from various disciplines participated in 24 sessions with 18 participants in each (12 only in the sessions with the Control treatment). Table 1 reports summary statistics on sessions. The proportion of female participants exceeds $50 \%$ in all treatments (binomial test, $p<0.001$ ); thus we control for a possible gender effect in the regression analysis.

\section{(Insert Table 1 about here)}

The experiment was computerized using the REGATE software. Upon arrival, subjects were randomly assigned to a computer. Talking was not allowed. Instructions were distributed and read aloud after completion of each part. We checked that each subject understood correctly the instructions and all questions were answered in private. Before the beginning of the first part, subjects were allowed to practice the task during two minutes to minimize learning effects during the rest of the session. Each session lasted about 90 minutes, including a final demographic survey and payment in private. Subjects earned on average 45 Yuan (\$7.38), which corresponds to approximately a 90 minute-wage for a part-time job in Beijing.

\subsection{Behavioral conjectures}

Predictions based on standard theory with selfish preferences and purely extrinsic motivation are straightforward. Since individuals are paid a fixed wage, they should exert no effort in any part. Individuals should not pay to avoid exposure and the threat of exposure should not affect effort since exposure does not impact payoffs. These predictions hold for all treatments and conditions.

However, instead of maximizing their monetary payoff, individuals may try to maximize their utility that depends on various sources of motivation. In particular, as in Benabou and Tirole (2006), an individual's utility may depend on extrinsic motivation (how much he values money), 
intrinsic motivation (how much he enjoys performing the task), and image motivation (how much he cares about his own and other's exposure). Utility is affected negatively by the variable cost of providing effort and the fixed cost of preserving image if the individual actually pays the fee. Image motivation enters negatively in the utility function if one assumes that public exposure entails a loss of image. .An individual with image concern will suffer a loss if he is exposed or if somebody else is exposed, but this loss is expected to be lower than when he experiences exposure himself. Of course, there should be no image utility loss if the individual has no image concern or if exposure is waived. Thus, when deciding whether or not to pay a fee, the individual compares the amount of the fee to the image loss he would suffer in case of public exposure accounting for his belief about other triad members' decisions whether to pay the fee. Moreover, avoiding the loss of image should also create an additional incentive to exert effort in part 3 whereas actual exposure may crowd-out effort in the future.

We summarize our initial conjectures as follows:

Conjecture 1. Image-concerned individuals pay the fee to avoid public exposure.

Conjecture 2. Individuals are more likely to pay the fee for avoiding their own exposure than for avoiding the exposure of another member.

Conjecture 3. The cost of exposure in terms of image increases the individual's level of effort in the part where there is a risk of being exposed.

Conjecture 4. The exposure of the least performers crowds-out their future intrinsic motivation.

Manipulating group identity should have no impact on the willingness to pay the fee if saving others' face is a general social norm. Alternatively, the utility loss experienced may depend on the identity of the subject at risk. Indeed, compared to the Baseline the loss may be higher when the individual at risk is an in-group and lower when he is an out-group or a random stranger. Manipulating group identity may also affect the beliefs about others' willingness to pay the fee, increasing them when the least performer is an in-group, decreasing them in the other cases. It may help solving the coordination problem regarding who should pay the fee in heterogeneous triads, as an individual should be more likely to pay the fee when the least performer is an in-group and the other triad member an out-group. Additionally, effort should be 
affected by the composition of the group, except if saving face is a general social norm. Being matched with out-groups or strangers may boost performance to reduce the risk of being the least performer, as one may expect less help from others in these conditions.

We state the following alternative conjectures:

Conjecture 5. Saving face is a general social norm. Varying social distance has no impact on the willingness to pay to avoid the public exposure of the least performers.

$V s$. Conjecture 5bis. The willingness to pay the fee is higher when the least performer belongs to the same triad or holds the same label, than when he is an out-group or a random stranger.

Conjecture 6. Being matched with out-groups in the Heterogeneous treatment or receiving the Random treatment boosts effort if individuals are willing to reduce their risk of exposure.

Vs. Conjecture 6bis. Effort is not affected by the composition of the triad in terms of identity.

\section{RESULTS}

We first examine the decision to pay for avoiding public exposure. Next, we focus on the emotions reported by the participants and finally, we study the effort levels.

Avoidance of public exposure

Table 2 displays summary statistics for the payment of the fee to avoid the public exposure of the least performer, by treatment and by performance rank in the triad in part 3 . The last column gives the percentage of least performers who are actually exposed.

(Insert Table 2 about here)

Table 2 shows that on average, $75 \%$ of the least performers in the Baseline are willing to pay to avoid being publicly exposed. This percentage is $80.95 \%$ in the Homogenous treatment, $71.43 \%$ in the Heterogeneous treatment, and $62.50 \%$ in the Random treatment. Pairwise proportion tests indicate that these values do not differ from the Baseline (two-sided, $p=0.569,0.754$, and 0.350, respectively). This is confirmed by a Kruskal-Wallis test $(p=0.853)$. Thus, most subjects have a concern for self-image, which gives support to Conjecture 1.

Table 2 also shows that in the Baseline a majority of subjects who are not personally at risk of public exposure $(54.17 \%$ of the best and the medium performers) choose to pay to waive the exposure of the least performer in their triad. This documents the importance of saving others' 
face. Interestingly, there is no significant difference between this percentage and the percentage in the Homogeneous treatment $(58.33 \%, p=0.642)$ and in the Heterogeneous treatment, regardless of whether the subject at risk is an in-group $(60.61 \%, p=0.565)$ or an out-group $(52.94 \%, p=0.903)$ (pairwise comparisons, two-sided proportion tests). A Kruskal-Wallis test confirms that there are no significant differences between the Baseline and the other treatments $(p=0.862)$.

Another important finding is that the percentage of subjects who are not at risk personally and who are willing to pay the fee in the Random treatment is $37.50 \%$. Two-sided proportion tests indicate that this differs significantly from the Baseline ( $p=0.101)$, the Homogeneous treatment $(p=0.021)$ and the Heterogeneous treatment when the least performer is an in-group $(p=0.041)$. It is significantly lower than when the least performer is an out-group but only if we consider a one-sided test $(p=0.065)$. A Kruskal-Wallis test indicates a significant difference between the Random and the other treatments $(p=0.017)$. Although this percentage is lower than in most of the other treatments, it should still be considered remarkably high since in this treatment the social distance with the least performer is larger than in most other treatments. ${ }^{11}$

As a consequence, the proportion of least performers who are actually publicly exposed varies from $28.57 \%$ in the Homogenous treatment, $33.33 \%$ in the Heterogeneous treatment, $37.50 \%$ in the Baseline, to $66.67 \%$ in the Random treatment. Proportion tests indicate that there is no significant difference between the first three treatments $(p>0.100)$ while the Random treatment differs from the Baseline $(p=0.043)$, the Homogeneous treatment $(p=0.003)$ and the Heterogeneous treatment $(p=0.009)$.

In accordance with Conjecture 2, people are more likely to incur a cost for avoiding their own exposure than for waiving the exposure of another member. Indeed, tests confirm that the proportion of subjects who choose to pay the fee is higher among those who are at risk than

\footnotetext{
${ }^{11}$ The analysis of beliefs indicates, however, that the individuals are more pessimistic about others' willingness to pay the fee when they are matched with out-groups rather than with in-groups. The mean beliefs about the number of other triad members choosing to pay the fee are $1.36($ S.D. $=0.68)$ in the Baseline, $1.42($ S.D. $=0.73)$ in the Homogenous treatment, 1.11 (S.D. $=0.74)$ in the Heterogeneous treatment, and 1.22 (S.D. $=0.75)$ in the Random treatment. Beliefs differ significantly between the Heterogeneous treatment on the one hand and the Baseline $(p=0.096)$ and the Homogenous treatment $(p=0.010)$ on the other hand (Mann-Whitney tests with each participant taken as one independent observation). They do not differ between the Random and the other treatments $(p>0.01)$.
} 
among others (one-sided, $p=0.044$ in the Baseline, $p=0.006$ in the Homogenous treatment, $p=0.046$ in the Heterogeneous treatment, and $p=0.022$ in the Random treatment). The least performers hold also more pessimistic beliefs about the number of members who choose to pay. ${ }^{12}$

Table 3 reports an analysis of the determinants of the willingness to pay the fee to prevent the public exposure of the least performer. It displays marginal effects from the estimates of five Probit models. In model (1), the independent variables include a dummy variable for each treatment, with the Baseline taken as the reference category. They include a dummy variable for the sessions in which we elicited beliefs on the number of triad members willing to pay the fee and two dummy variables indicating whether the subject has got the first or the third rank, respectively, with the second rank taken as the reference. Model (2) augments model (1) with two variables capturing the beliefs that one or two other triad members choose to pay the fee (compared to none) interacted with the dummy variable for the belief elicitation condition. The aim is to test whether subjects try to solve a coordination problem, i.e. whether they are more (less) likely to pay the fee when they believe that one (two) other triad member will pay. Model (3) re-estimates model (2) on the sub-sample of the least performers. We include an additional dummy variable indicating whether the least performer is matched with two out-groups in the Heterogeneous treatment. Model (4) re-estimates model (2) on the sub-sample of the best and medium performers, after including a dummy variable that indicates whether the least performer is an out-group in the Heterogeneous treatment. Finally, model (5) restricts the observations to the best and medium performers in the Heterogeneous treatment. It tests the hypothesis that the subject's willingness to pay is reduced when being matched with two out-groups and when the least performer is the only out-group in the triad. The reference category is the case in which the least performer is the subject's in-group. It also controls for the belief elicitation condition and the belief on the number of other triad members willing to pay the fee. ${ }^{13}$ In the five models, we

\footnotetext{
12 The mean beliefs of the least performers are 1.08 (S.D. $=0.67)$ in the Baseline, $1.25($ S.D. $=0.79)$ in the Homogenous treatment, 0.87 (S.D. $=0.74)$ in the Heterogeneous treatment, and $0.83($ S.D. $=0.76)$ in the Random treatment. They are significantly more pessimistic than others in the Baseline $(p=0.070)$, Heterogeneous $(p=0.057)$ and Random treatments ( $p=0.002)$ (Mann-Whitney tests), not in the Homogeneous treatment $(p=0.185)$.

${ }^{13}$ This last variable replaces the separate belief variables included in the previous models because there is not enough variation in the decision to pay the fee when the subjects believe that the two other members will pay. $52.78 \%$
} 
control for demographic variables, including gender, age and family relative wealth. As these variables were never significant, we omit reporting their marginal effects.

(Insert Table 3 about here)

Model (2) shows that a least performer is $24.13 \%$ more likely to choose to pay the fee than a subject who receives the second rank, with no difference between subjects who get ranks 1 and 2 , respectively. This supports Conjecture 2. Second, models (1) and (2) indicate that being in a triad with in-groups only (i.e., in the Homogeneous treatment) or with out-groups (i.e., in the Heterogeneous treatment) does not affect the willingness to pay the fee as compared to the Baseline, controlling or not for the beliefs about others' willingness to pay the fee. In contrast, in the Random treatment where the social distance between players is larger, the willingness to pay the fee is reduced by $16.19 \%$ compared to the Baseline. The difference between the Random and the Baseline treatments is, however, not significant for the least performers (model (3)).

The third finding relates to the triad configuration in terms of group identity in the Heterogeneous treatment. In this treatment, neither the least performers (model (3)) nor the other triad members (models (4) and (5)) condition their willingness to pay on the triad composition. This tends to support Conjecture 5 against Conjecture 5bis.

The fourth finding is related to beliefs. While model (1) shows that eliciting beliefs did not change subjects' behavior, all the other models find that subjects' willingness to help increases in the number of triad members they believe will also pay. For example, model (2) shows that, compared to the condition where we did not elicit beliefs, predicting that no one will pay decreases one's willingness to pay by $29.30 \%$, predicting that one other member will pay increases it by $19.76 \%$, and predicting that the two other members will pay even increases it by $62.95 \%$. For the least performers (model (3)), these percentages are $-26.89 \%, 40.41 \%$ and $46.23 \%$, respectively. For the best and medium performers (model (4)), believing that one other member will pay has no impact, but believing that the two others will pay increases one's own

of subjects with rank 1 or 2 are willing to pay in the condition where we do not elicit beliefs, $25 \%$ when they believe that none of the two others will pay, $33.33 \%$ when they believe that one will pay but $100 \%$ when they believe that the two others will pay. 
willingness to pay by $57.76 \%$, while believing that no one is paying reduces this willingness by $22.09 \%$. This rejects an interpretation in terms of coordination which would require that one is more willing to pay when expecting that a single other member chooses to pay. Our finding suggests instead that subjects choose to pay because preserving image is a strong social norm, strengthening the support to Conjecture $5 .^{14}$

We summarize these findings as follows:

Result 1: A large majority of individuals are willing to pay a price to avoid their public exposure and this willingness increases in the beliefs about the intensity of help expected from others, which supports Conjecture 1.

Result 2: A smaller majority of individuals are willing to incur a cost to waive the exposure of other people, which supports Conjecture 2.

Result 3: Even when there is no group identity, more than one third of subjects are still willing to preserve others' face. The group composition in terms of identity has relatively little impact on behavior. Together with the increase in the willingness to pay with the belief on others' willingness to help, this suggests that protecting others' face is a strong social norm, supporting Conjecture 5 against Conjecture 5bis.

\section{Emotions}

In this section we explore whether the strong willingness to preserve one's and others' face is driven by the fact that the ranking of subjects and the threat of exposure generate more unpleasant and less pleasurable emotions. Figures 1 and 2 display the evolution of self-reported levels of shame and happiness over time, by subjects' rank in part 3 and according to actual public exposure for the least performers. We consider the feelings reported at the beginning of the session, after receiving feedback on one's score in part 1, after receiving feedback on scores and ranks in part 2, after deciding on paying the fee in part 3, after the public exposure of the least performers, and after the feedback on scores and ranks in part 4. All non-parametric tests reported here are two-sided and consider each individual as an independent observation.

\section{(Insert Figures 1 and 2 about here)}

\footnotetext{
14 In other regressions not reported here but available upon request, we also controlled for the difference in scores between the player and the least performer in the triad. The coefficient of this variable is never significant. This supports the idea that helping to save face is a strong norm that is not even conditioned on differences in effort.
} 
The figures show no difference in shame and happiness between the categories of subjects at the beginning of the session or when receiving feedback in part 1 (Mann-Whitney tests - MW hereafter,$- p>0.010$ in pairwise comparisons). When learning their rank in part 2 , the least performers in part 3 start experiencing more shame and less happiness than subjects with rank 1 or 2 (MW, $p<0.001$ ), while the best performers in part 3 start experiencing more happiness than the others (MW, $p<0.001){ }^{15}$ The figures show that the least performers' emotions are exacerbated in part 3 when learning their risk of being exposed. In this part too, the differences with the levels of emotions reported by the other players are significant (MW, $p<0.001)$.

The figures reveal three interesting findings about the emotions experienced after public exposure. First, the publicly exposed subjects report a level of shame similar to the level reported before knowing the decision of their triad members (Wilcoxon test $-\mathrm{W}$ hereafter,$- p=0.522$ ); this suggests that anticipatory feelings are as strong as those experienced at the time of exposure. Their level of shame decreases in part 4 compared to the moment of exposure (W test, $p=0.008$ ) without returning to its initial level when receiving the same type of feedback, such as in part 2 (W test, $p=0.033$ ), suggesting that it takes time to dissipate. Second, the least performers who have not been exposed experience an immediate decrease of their shame intensity at the time of exposure compared to when waiting for the decision of their triad members (W test, $p<0.001$ ) while their level of happiness peaks and exceeds that reported by the best performers (MW test, $p=0.005)$. In part 4 they still report a level of happiness that is higher than that reported by those who have been exposed (MW test, $p=0.004$ ). They may feel satisfaction from seeing that others helped them. Finally, the best performers in part 3 report a sharp decrease in happiness when the least performers are publicly exposed compared to when they decide to pay the fee (W test, $p<0.001$ ), which suggests empathy.

Of course, these feelings could be driven by the fact that individuals dislike being singled out, independently of any signaling value of a lower relative performance. Two elements suggest

\footnotetext{
15 There is indeed a relative stability in ranks across parts. $63 \%$ of the best performers in part 3 received already rank 1 in part 1,74\% received rank 1 both in part 2 and in part $4.65 \%$ of the least performers in part 3 received already rank 3 in part $1,76 \%$ in part 2 , and $74 \%$ in part 4 .
} 
that this interpretation is not the most likely. First, the least performers' shame increases and their happiness decreases already between part 1 (when receiving feedback on own score) and part 2 (when learning also the rank) (W tests, both $p<0.001$ ), signaling that a lower rank generates a change in emotions. Second, we ran two sessions of a game similar to the Baseline, except that it is the best performer who is publicly exposed unless at least one player pays to avoid exposure $(\mathrm{N}=36)$. In this treatment the percentage of best performers paying to avoid public praise is $33.33 \%$ (4 out of 12). A binomial test indicates that the probability to pay the fee for the least performers in the Baseline is significantly higher than this percentage $(p<0.001)$. We can reasonably conclude that what people try to avoid is mainly the exposure of a lower performance.

We summarize our analysis as follows:

Result 4: The subjects threatened of exposure and those who are actually exposed express shame and decreased happiness. Subjects who are not threatened also report a decrease in happiness at the moment of exposure. Empathy might be the mechanism behind the willingness to preserve others' face at a personal cost.

\section{Evolution of performance levels}

To study whether image influences performance, Table 4 displays descriptive statistics on mean performance in each part in the Control treatment (with no social information and no exposure) and in each other treatment for all subjects, and then only for the least performers in part 3 according to whether they were or not exposed (excluding the Control treatment).

\section{(Insert Table 4 about here)}

Table 4 attests of the presence of intrinsic motivation since subjects provide a positive level of effort in all parts although they are paid a fixed wage. Performance increases from part 1 to part 2 and from part 2 to part 3 in each treatment (W tests, $p<0.001$ ). This cannot be the result of the pressure of social comparisons and the risk of exposure since the same evolution is observed in the Control treatment. We find no significant difference in performance between the Control and each other treatment in any part (MW tests, $p>0.10$ ). This rejects Conjecture 3. Moreover, mean performance is not higher in the Heterogeneous than in the Homogenous treatment in any part (MW tests, $p>0.100$ ). Being matched with out-groups does not boost effort in part 3 to 
increase the negative externalities of one's effort on out-groups. This analysis supports Conjecture 6 against Conjecture 6bis.

The evolution of performance between parts 3 and 4 is more diverse. Although there is no more risk of exposure, performance is higher in part 4 than in part 3 in the Baseline and the Heterogeneous treatments (W tests, $p<0.001)$, but not in the other treatments $(p>0.10)$. Interestingly, when we pool all the treatments (excluding the Control), we find that both the subjects with ranks 1 or 2 and the least performers who have not been exposed in part 3 increase their effort in part $4(p<0.001)$, but not the least performers who have been exposed $(p=0.626)$. This observation suggests that actual exposure tends to crowd-out intrinsic motivation.

This finding is further supported by the OLS regressions on part 3 reported in Table 5. Model (1) is for the subjects who got rank 1 or 2 and model (2) for the least performers. The dependent variable is the difference in performance levels between part 4 and part 3 . The independent variables include dummy variables for each treatment, with the Control as the reference category, a dummy variable indicating whether the subject chose to pay the fee, an indicator of whether the least performer in the triad has been exposed, ${ }^{16}$ and the same demographic variables as in Table 3. Model (1) identifies no effect of exposure on the evolution of performance of the subjects who got rank 1 or 2 . In contrast, model (2) reveals a significant negative effect of exposure of the least performers on their future intrinsic motivation. Indeed, the performance of the exposed subjects decreases by 3.12 units between parts 3 and 4 compared to those who have been able to avoid exposure. This supports Conjecture 4 and leads to our final result.

\section{(Insert Table 5 about here)}

Result 5: While in general social information on relative performance and group identity has little impact on performance and its evolution, public exposure crowds-out the future intrinsic motivation of the least performers, which supports Conjecture 4.

\footnotetext{
16 These two dummy variables take value 0 in the Control treatment. We do not include the intensity of shame and happiness feelings in part 3 because they are not random variables and would create an endogeneity issue.
} 


\section{DISCUSSION AND CONCLUSION}

The importance of preserving self and others' image in social interactions is well known from negotiations and diplomacy, but it has received little attention in economics. Our experiment shows that most people are willing to forego some money to avoid the public display of a poor relative performance. We interpret this behavior as evidence of the fear of losing face since individuals report shame and a lower level of happiness when they learn about their lower rank. We can exclude that this behavior captures only distaste for exposure, because when it is the best performer who is exposed, a much lower proportion of players are willing to avoid it. This result is striking since subjects were paid a fixed wage, the task we used is trivial, and performance helps no-one. If people care about being exposed, this indicates that when there is intrinsic motivation the public exposure of a low rank is associated with a devaluated perception of the self in society. These findings suggest that anticipatory negative emotions inflict a moral cost to individuals that is higher than the monetary cost incurred to avoid exposure.

A second major finding is that a majority of individuals sacrifice resources to preserve others' face although there is no prospect of future personal benefits from this action. This empathic behavior shows that altruism extends beyond the monetary realm, as individuals like to do good to others also in terms of image. In our experiment the cost incurred to avoid others' exposure represents $10 \%$ of the income. A possible extension would be to vary this cost in order to measure the value of others' face.

Our manipulation of group identity has little direct effect on behavior. Belonging to a triad is the main source of group identity and adding labels to the triad group identity is of limited importance. But even when there is no triad formation more than one third of players who are not at risk are willing to help others. This may be due to the fact that in-group favoritism in this type of situation would be perceived as a violation of a social norm (Harris et al., 2012). It may also result from the fact that we conducted the study in China. Buchan et al. (2009) found that Chinese subjects sent and returned significantly more to out-groups than to in-groups in a trust game, while the opposite was found for American subjects. In collectivist cultures (Hofstede, 
1980), the goals of the group matter more than those of individuals, which could lead collectively oriented subjects to pay less attention to social distance. Cross-cultural replication studies would allow us to test whether in individualistic cultures people are less willing to sacrifice to save others' face and whether social distance has a stronger impact on this decision. Our expectation is that people would still sacrifice to help others, as previous studies in social sciences have shown that face maintenance is important also in Western cultures (Ting-Toomey et al., 1991).

Finally, we found that public exposure tends to crowd-out future intrinsic motivation at least in the short run. This suggests that providing feedback about relative performance may possibly encourage people to work harder, but when information is disseminated it also generates negative emotions and a lower level of satisfaction, the longer-term effects of which on individuals' performance are still to be explored.

\section{REFERENCES}

Abbink, Klaus, and Dona Harris, 2012. In-group Favouritism and Out-group Discrimination in Naturally Occurring Groups, Discussion Paper 616, University of Oxford.

Akerlof, George A. and Rachel E. Kranton, 2000. Economics and Identity, Quarterly Journal of Economics, 115(3), 715-53.

Andreoni, James, and John Miller, 2002. Giving According to GARP: An Experimental Test of the Consistency of Preferences for Altruism. Econometrica, 70(2), 737-753.

Alpizar, Francisco, Fredrik Carisson, and Olof Johansson-Stenman, 2008. Anonymity, reciprocity and conformity: evidence from voluntary contributions to a national park in Costa Rica, Journal of Public Economics, 92(5-6), 1047-1060.

Ariely, Dan, Anat Bracha, and Stephan Meier. 2009. Doing Good or Doing Well? Image Motivation and Monetary Incentives in Behaving Prosocially, American Economic Review, 99(1), 544-555.

Barankay, Iwan, 2012. Rank Incentives: Evidence from a Randomized Workplace Experiment, Working Paper University of Pennsylvania.

Baumeister, Roy F., Jennifer D. Campbell, Joachim I. Krueger and Kathleen D. Vohs, 2005. Exploding the Self-Esteem Myth, Scientific American, 292, 84-91.

Benabou, Roland, and Jean Tirole, 2006. Incentives and prosocial behavior, American Economic Review, 96(5), 1652-1678. 
Ben-Ner, Avner, Brian P. McCall, Stephane Massoud, and Hua Wang, 2009. Identity and in-group/out-group differentiation in work and giving behaviors: Experimental evidence, Journal of Economic Behavior \& Organization, 72, 153-170.

Beresford, Alastair, Dorothea Kübler, and Sören Preibusch, 2012. Unwillingness to pay for privacy: A field experiment, Economics Letters, 117(1), 25-27.

Bernhard, Helen, Ernst Fehr, and Urs Fischbacher, 2006. Group Affiliation and Altruistic Norm Enforcement, American Economic Review, 96(2), 217-221.

Bohnet, Iris, and Bruno Frey, 1999. The sound of silence in prisoner's dilemma and dictator games, Journal of Economic Behavior \& Organization, 38 (1), 43-57.

Bowles, Samuel, and Herbert Gintis, 2004. Persistent Parochialism: Trust and Exclusion in Ethnic Networks, Journal of Economic Behavior \& Organization, 55(1), 1-23.

Bradler, Christiane, Robert Dur, Susanne Neckermann, and Arjan Non, 2013. Employee Recognition and Performance: A Field Experiment, CESifo Working Paper 4164. Available at SSRN: http://ssrn.com/abstract=2243458

Buchan, Nancy R., Rachel Croson, and Eric J. Johnson. 2006. Let's Get Personal: An International Examination of the Influence of Communication, Culture and Social Distance on Other Regarding Preferences, Journal of Economic Behavior \& Organization, 60, 373-398.

Cappelen, Alexander W., Trond Halvorsen, Erik Ø. Sørensen, and Bertil Tugodden, 2012. Face-saving or fair-minded: What motivates moral behavior?, Working Paper, Norwegian School of Economics, Bergen.

Chakravarty, Surajeet, and Miguel A. Fonseca, 2011. The effect of social fragmentation on public good provision: an experimental study, Discussion Paper 1207, Exeter University.

Charness, Gary, and Matthew Rabin. 2002. Understanding Social Preferences with Simple Tests, Quarterly Journal of Economics, 117, 817-869.

Charness, Gary, Luca Rigotti, and Aldo Rustichini, 2007. Individual Behavior and Group Membership, American Economic Review, 97(4), 1340-1352.

Charness, Gary, and Uri Gneezy, 2008. What's in a name? Anonymity and social distance in dictator and ultimatum games, Journal of Economic Behavior \& Organization, 68 (1), 29-35.

Charness, Gary, David Masclet, and Marie Claire Villeval, 2014. The Dark Side of Competition for Status, Management Science, 60(1), 38-55.

Chen, Yan, and Sherry Xin Li, 2006. Group Identity and Social Preferences, American Economic Review, 99(1), 431-457.

Coricelli, Giorgio, Mateus Joffily, Claude Montmarquette, and Marie Claire Villeval, 2010. Cheating, emotions, and rationality: an experiment on tax evasion, Experimental Economics, $13,226-247$. 
Coricelli, Giorgio, Elena Rusconi, and Marie Claire Villeval, 2014. Tax Evasion and emotions in repeated interactions: An empirical test of re-integrative shaming theory, Journal of Economic Psychology, 40, 49-61..

Eckel, Catherine C., Enrique Fatas, and Rick Wilson, 2010. Cooperation and Status in Organizations, Journal of Public Economic Theory, 12(4), 737-762.

Ellingsen, Tore, and Magnus Johannesson, 2007. Paying respect, Journal of Economic Perspectives, 21(4), 135-149.

Ellingsen, Tore, and Magnus Johannesson, 2008a. Pride and prejudice: the human side of incentive theory, American Economic Review, 98(3), 990-1008.

Ellingsen, Tore, and Magnus Johannesson, 2008b. Anticipated verbal feedback induces altruistic behaviour, Evolution and Human Behaviour, 29(2), 100-105.

Eriksson, Tor, and Marie Claire Villeval, 2011. Respect and relational contracts, Journal of Economic Behavior \& Organization, 81, 286-298.

Ewers, Mara, and Florian Zimmermann, 2015. Image and Misreporting, Journal of the European Economic Association 13(2), 363-380.

Falk, Armin, and Urs Fischbacher, 2006. A theory of reciprocity, Games and Economic Behavior, 54(2), 293-315.

Fehr, Ernst, and Klaus M. Schmidt, 1999. A theory of fairness, competition and cooperation Quarterly Journal of Economics, 114(3), 817-868.

Fehr, Ernst, and Urs Fischbacher, 2003. The nature of human altruism, Nature, 425, 785-791.

Feri, Francesco, Caterina Gianetti, and Nicola Jentzsch, 2013. Disclosure of Personal Information Under Risk of Privacy Shocks, mimeo, DIW Berlin.

Fershtman, Chaim, and Uri Gneezy, 2001. Discrimination in a Segmented Society: An Experimental Approach, Quarterly Journal of Economics, 116(1), 351-377.

Galeotti, Fabio, and Daniel J. Zizzo (2014). What happens if you single out? An experiment, Social Choice and Welfare, 43(3), 703-729.

Gneezy, Uri, and Aldo Rustichini, 2000. A fine is a price, Journal of Legal Studies, 29, 1-17.

Goette, Lorenz, David Huffman and Stephan Meier, 2006. The Impact of Group Membership on Cooperation and Norm Enforcement: Evidence Using Random Assignment to Real Social Groups, American Economic Review, 96(2), 212-216.

Goette, Lorenz, David Huffman and Stephan Meier, 2012a. The Impact of Social Ties on Group Interactions: Evidence from Minimal Groups and Randomly Assigned Real Groups, American Economic Journal: Microeconomics, 4(1), 101-115.

Goette, Lorenz, David Huffman, Stephan Meier, and Matthias Sutter, 2012b. Competition 
Between Organizational Groups: Its Impact on Altruistic and Anti-Social Motivations, Management Science, 58(5), 948-960.

Goffman, Erving (2005). Interaction Ritual: Essays in Face-to-Face Behavior. Aldine Transaction.

Guala, Francesco, Luigi Mittone, and Matteo Ploner, 2013. Group membership, team preferences and expectations, Journal of Economic Behavior \& Organization, 86 (C), 183-190.

Hargreaves-Heap, Shaun P., and Daniel J. Zizzo, 2009. The Value of Groups, American Economic Review, 99(1), 295-323.

Harris, Donna, Benedikt Herrmann, and Andreas Kontoleon, 2009. Two’s Company, There's a Group: The Impact of Group Identity and Group Size on In-Group Favouritism, CeDex Discussion Paper 2009-13, Nottingham.

Harris, Donna, Benedikt Herrmann, and Andreas Kontoleon, 2012. When to favour your own group? The threats of costly punishments and in-group favoritism. Discussion Paper 628, University of Oxford.

Herbst, Luisa, Kai A. Konrad, and Florian Morath, 2012. Endogenous group formation in experimental contests, Working Paper of the Max Planck Institute for Tax Law and Public Finance 2012-10. Available at SSRN: http://ssrn.com/abstract=2166206.

Ho, David Yau-Fai, 1976. On the Concept of Face, American Journal of Sociology, 81(4), 867-884.

Hofstede, Geert H., 1980. Culture's Consequences. Berkeley: University of California Press.

Hopfensitz, Astrid, and Ernesto Reuben, 2009. The importance of emotions for the effectiveness of social punishment, The Economic Journal, 119(540), 1534-59.

$\mathrm{Hu}$, Hsien Chin, 1944. The Chinese Concept of 'Face', American Anthropologist, 46 (1), 45-64.

Hugh-Johns, David, and David Reinstein, 2010. Losing Face, Jena Working Paper 2013-068.

Johansson-Stenman, Olof, and Henrik Svedsater, 2012. Self-image and valuation of moral goods: stated versus real willingness to pay, Journal of Economic Behavior \& Organization, 84(3), 879-891.

Johansson-Stenman, Olof, and Peter Martinsson, 2006. Honestly, why are you driving a BMW? Journal of Economic Behavior \& Organization, 60(2), 129-146.

Kato, Takao, and Pian Shu, 2013. Competition and Social Identity in the Workplace: Evidence from a Chinese Textile Firm, Harvard Business School Working Paper 14-011.

Kollock, Peter, 1998. Transforming Social Dilemmas: Group Identity and Cooperation, in Peter A. Danielson, ed., Modeling Rationality, Morality and Evolution. Oxford: Oxford University Press, 186-210.

Kosfeld, Michael, Susanne Neckermann, 2011. Getting more work for nothing? Symbolic awards 
and worker performance, American Economic Journal: Microeconomics, 3(1), 1-16.

Koszegi, Botond, 2006. Ego Utility, Overconfidence and Task Choice, Journal of the European Economic Association, 4(4), 673-707.

Kuhnen, Camelia M., and Agnieszka Tymula, 2012. Feedback, Self-Esteem and Performance in Organizations, Management Science, 58, 94-113.

Lacetera, Nicola, and Mario Macis, 2010. Social image concerns and prosocial behavior: field evidence from a nonlinear incentive scheme, Journal of Economic Behavior \& Organization, 76(2), 225-237.

Masella, Paolo, Stephen Meier, and Philipp Zahn, 2014. Incentives and Group Identity, Games and Economic Behavior, 86, 12-25.

Mruk, Christopher J., 2006. Self-Esteem Research, Theory, and Practice: Toward a Positive Psychology of Self-Esteem. 3rd Edition. New-York: Springer.

Pan, Xiaofei S., and Daniel Houser, 2011. Competition for Trophies Triggers Male Generosity, PLOS ONE 6(4):e18050.

Qi, Xiaoying (2011). Face: A Chinese Concept in a Global Sociology, Journal of Sociology, 47, 279-296.

Redding, S. Gordon, and Michael Ng, 1982. The Role of 'Face' in the Organizational Perceptions of Chinese Managers, Organization Studies, 3(3), 201-219.

Smith, Richard H., J. Matthew Webster, W. Gerrod Parrott, and Heidi L. Eyre, 2002. The role of public exposure in moral and non moral shame and guilt, Journal of Personality and Social Psychology, 83(1), 138-159.

Spencer, Steven J., Steven Fein, Christine D. Lomore, 2001. Maintaining One's Self-Image Vis-à-Vis Others: The Role of Self-Affirmation in the Social Evaluation of the Self, Motivation and Emotion, 25(1), 41-65.

Spencer-Oatey, Helen, 2007. Theories of identity and the analysis of face, Journal of Pragmatics, 39(4), 639-656.

Tajfel, Henri, Michael G. Billig, Robert P. Bundy, and Claude Flament, 1971. Social Categorization and Intergroup Behavior, European Journal of Social Psychology, 1(2), 149-178.

Tajfel, Henri, and John Turner, 1979. An integrative theory of intergroup conflict, in William Austin and Stephen Worchel, Eds., The Social Psychology of Intergroup Relations, Monterey: CA, Brooks/Cole.

Ting-Toomey, Stella, 2005. The Matrix of Face: An Updated Face-Negotiation Theory, in W.B. Gudykunst, ed., Theorizing About Intercultural Communication. Thousand Oaks: Sage, 71-92.

Ting-Toomey, Stella, Ge Gao, Paula Trubiski, Zhizhong Yang, Hak Soo Kim, Sung-Ling Lin, 
Tsukasa Nishida. 1991. Culture, face maintenance, and styles of handling interpersonal conflict: a study in five cultures, International Journal of Conflict Management, 2(4), 275 296.

Tran, Ahn, and Richard Zeckhauser, 2012. Rank as an Incentive: Evidence from a Field Experiment, Mimeo Harvard University.

Xiao, Erte, and Daniel Houser, 2011. Punish in public, Journal of Public Economics, 95(7-8), 1006-1017.

Yang, Kuo-Shu (ed.), 1989. The Psychology of the Chinese. Taipei: Kui-Kuan Books.

Zizzo, Daniel J., 2011. You are not in my boat: common fate and discrimination against outgroup members, International Review of Economics, 58, 91-103. 


\section{TABLES AND FIGURES}

Table 1. Summary of sessions

\begin{tabular}{lccccc}
\hline \multicolumn{1}{c}{ Treatments } & $\begin{array}{c}\text { Nb of } \\
\text { sessions }\end{array}$ & $\begin{array}{c}\text { Nb of sessions with } \\
\text { belief elicitation }\end{array}$ & $\begin{array}{c}\text { Number of } \\
\text { participants }\end{array}$ & $\begin{array}{c}\text { Mean age } \\
\text { (years) }\end{array}$ & \% males \\
\hline Baseline & 4 & 2 & 72 & 22.24 & 15.28 \\
Homogenous & 7 & 4 & 126 & 21.91 & 26.98 \\
Heterogeneous & 7 & 4 & 126 & 22.25 & 28.57 \\
Random & 4 & 4 & 72 & 22.19 & 29.17 \\
Control & 2 & 0 & 24 & 21.25 & 20.83 \\
\hline Total & 24 & 14 & 420 & 22.09 & $25.48 \%$ \\
\hline \hline
\end{tabular}


Table 2. Percentages of participants paying the fee to avoid the public exposure of the least performers, by treatment and by performance rank, and actual exposure

\begin{tabular}{lcccc}
\hline Treatments & $\begin{array}{c}\text { Rank 1 } \\
\text { in part 3 }\end{array}$ & $\begin{array}{c}\text { Rank 2 } \\
\text { in part 3 }\end{array}$ & $\begin{array}{c}\text { Rank 3 } \\
\text { in part 3 }\end{array}$ & $\begin{array}{c}\% \text { of least } \\
\text { performers } \\
\text { exposed }\end{array}$ \\
\hline Baseline & $54.17 \%(13 / 24)$ & $54.17 \%(13 / 24)$ & $75.00 \%(18 / 24)$ & $37.50 \%(9 / 24)$ \\
Homogenous & $50.00 \%(21 / 42)$ & $66.67 \%(28 / 42)$ & $80.95 \%(34 / 42)$ & $28.57 \%(12 / 42)$ \\
Heterogeneous & $57.14 \%(24 / 42)$ & $54.76 \%(23 / 42)$ & $71.43 \%(30 / 42)$ & $33.33 \%(14 / 42)$ \\
$\quad$ - KKk or kkK & $33.33 \%(3 / 9)$ & $44.44 \%(4 / 9)$ & $66.67 \%(6 / 9)$ & $44.44 \%(4 / 9)$ \\
$\quad$ Kkk or kKK & $69.23 \%(9 / 13)$ & $61.54 \%(8 / 13)$ & $69.23 \%(9 / 13)$ & $30.00 \%(6 / 13)$ \\
$\quad$ KkK or kKk & $60 \%(12 / 20)$ & $55 \%(11 / 20)$ & $75 \%(15 / 20)$ & $20 \%(4 / 20)$ \\
Random & $33.33 \%(8 / 24)$ & $41.67 \%(10 / 24)$ & $62.50 \%(15 / 24)$ & $66.67 \%(16 / 24)$ \\
\hline Total & $50.00 \%(66 / 132)$ & $56.06 \%(74 / 132)$ & $73.48 \%(97 / 132)$ & $38.64 \%(51 / 132)$ \\
\hline
\end{tabular}

Note: "K" is for the Kandinsky group, "k" for Klee group. "KKk or kkK" reads as follows: in the triad, the participants who get the first and the second ranks have the same group identity while the least performer has another group identity. 
Table 3. Determinants of the decision to pay the fee to avoid the public exposure of the least performer

\begin{tabular}{|c|c|c|c|c|c|}
\hline \multirow{2}{*}{$\begin{array}{l}\text { Dependent variable: } \\
\text { Decision to pay the fee }\end{array}$} & \multicolumn{5}{|c|}{ Probit models } \\
\hline & $\begin{array}{c}\text { All } \\
\text { subjects } \\
(1)\end{array}$ & $\begin{array}{c}\text { All } \\
\text { subjects } \\
(2)\end{array}$ & $\begin{array}{c}\text { Rank } 3 \\
\text { only } \\
(3)\end{array}$ & $\begin{array}{c}\text { Ranks } \\
1 \text { and } 2 \\
(4)\end{array}$ & $\begin{array}{c}\text { Ranks } 1 \text { and } \\
2 \text { - Hetero. T } \\
\text { (5) }\end{array}$ \\
\hline Baseline treatment & Ref. & Ref. & Ref. & Ref. & - \\
\hline Homogenous treatment & $\begin{array}{c}0.022 \\
(0.063)\end{array}$ & $\begin{array}{c}0.033 \\
(0.064)\end{array}$ & $\begin{array}{c}0.077 \\
(0.101)\end{array}$ & $\begin{array}{c}0.022 \\
(0.077)\end{array}$ & - \\
\hline Heterogeneous treatment & $\begin{array}{c}0.040 \\
(0.063)\end{array}$ & $\begin{array}{c}0.036 \\
(0.063)\end{array}$ & $\begin{array}{c}0.004 \\
(0.106)\end{array}$ & $\begin{array}{c}0.069 \\
(0.096)\end{array}$ & - \\
\hline Random treatment & $\begin{array}{c}-0.155^{* *} \\
(0.075)\end{array}$ & $\begin{array}{c}-0.162 * * \\
(0.075)\end{array}$ & $\begin{array}{l}-0.048 \\
(0.120)\end{array}$ & $\begin{array}{c}-0.225 * * \\
(0.095)\end{array}$ & - \\
\hline$i$ is Rank 2 in part 3 & Ref. & Ref. & - & Ref. & Ref. \\
\hline$i$ is Rank 1 in part 3 & $\begin{array}{l}-0.066 \\
(0.051)\end{array}$ & $\begin{array}{l}-0.071 \\
(0.052)\end{array}$ & - & $\begin{array}{l}-0.071 \\
(0.053)\end{array}$ & $\begin{array}{c}0.055 \\
(0.100)\end{array}$ \\
\hline$i$ is Rank 3 in part 3 & $\begin{array}{l}0.253 * * * \\
(0.051)\end{array}$ & $\begin{array}{c}0.241 * * * \\
(0.052)\end{array}$ & - & - & - \\
\hline $\begin{array}{l}\text { Heterogeneous T. } * \text { Rank } 3 \\
\text { is an out-group }\end{array}$ & - & - & - & $\begin{array}{c}0.001 \\
(0.094)\end{array}$ & - \\
\hline Rank 3 is $i$ 's in-group & - & - & - & - & Ref. \\
\hline Rank 3 is the only out-group & - & - & - & - & $\begin{array}{l}-0.091 \\
(0.132)\end{array}$ \\
\hline $\begin{array}{l}\text { Heterogeneous T. } * \\
i \text { matched with } 2 \text { out-groups }\end{array}$ & - & - & $\begin{array}{c}0.007 \\
(0.136)\end{array}$ & - & $\begin{array}{l}0.090 \\
(0.111)\end{array}$ \\
\hline Belief elicitation & $\begin{array}{c}0.042 \\
(0.053)\end{array}$ & $\begin{array}{c}-0.293 * * * \\
(0.073)\end{array}$ & $\begin{array}{c}-0.269 * * * \\
(0.085)\end{array}$ & $\begin{array}{l}-0.221 * * \\
(0.105)\end{array}$ & $\begin{array}{c}-0.504 * * * \\
(0.146)\end{array}$ \\
\hline $\begin{array}{l}\text { Belief elicitation } * \\
\text { Belief: } 1 \text { other pays }\end{array}$ & - & $\begin{array}{c}0.198 * * * \\
(0.076)\end{array}$ & $\begin{array}{c}0.404 * * * \\
(0.083)\end{array}$ & $\begin{array}{l}-0.010 \\
(0.114)\end{array}$ & - \\
\hline $\begin{array}{l}\text { Belief elicitation * } \\
\text { Belief: } 2 \text { others pay }\end{array}$ & - & $\begin{array}{c}0.630 * * * \\
(0.066)\end{array}$ & $\begin{array}{c}0.462 * * * \\
(0.106)\end{array}$ & $\begin{array}{c}0.578 * * * \\
(0.097)\end{array}$ & - \\
\hline $\begin{array}{l}\text { Belief elicitation * } \\
\text { Belief nb others pay }\end{array}$ & - & - & - & - & $\begin{array}{c}0.463 * * * \\
(0.089)\end{array}$ \\
\hline Demographics & Yes & Yes & Yes & Yes & Yes \\
\hline $\begin{array}{l}\text { N } \\
\text { Log-likelihood } \\
\text { LR Chi }{ }^{2} \\
\text { Prob>Chi } \\
\text { Pseudo }{ }^{2} \\
\end{array}$ & $\begin{array}{c}394 \\
-249.638 \\
30.57 \\
<0.001 \\
0.058 \\
\end{array}$ & $\begin{array}{c}394 \\
-210.279 \\
109.28 \\
<0.001 \\
0.206 \\
\end{array}$ & $\begin{array}{c}132 \\
-61.440 \\
29.81 \\
<0.001 \\
0.195 \\
\end{array}$ & $\begin{array}{c}262 \\
-138.295 \\
85.38 \\
<0.001 \\
0.236 \\
\end{array}$ & $\begin{array}{c}84 \\
-45.081 \\
25.09 \\
0.002 \\
0.218 \\
\end{array}$ \\
\hline
\end{tabular}

Notes: The Table reports marginal effects. $* * *$ indicate significance at the $1 \%$ level, $* *$ at the $5 \%$ level and $*$ at the $10 \%$ level. 
Table 4. Mean performance, by part and by treatment

\begin{tabular}{lccccc}
\hline & Part 1 & Part 2 & Part 3 & Part 4 & $\mathrm{N}$ \\
\hline Control treatment & $128.54(16.09)$ & $133.50(17.16)$ & $138.58(15.34)$ & $140.17(13.01)$ & 24 \\
\hline Baseline treatment & $127.14(11.41)$ & $132.56(14.93)$ & $136.08(16.64)$ & $138.86(17.64)$ & 72 \\
Homogenous treatment & $126.61(15.36)$ & $135.28(14.82)$ & $140.10(13.60)$ & $140.70(15.45)$ & 126 \\
Heterogeneous treatment & $127.12(13.13)$ & $133.31(14.38)$ & $138.67(15.50)$ & $140.17(17.06)$ & 126 \\
Random treatment & $130.11(14.41)$ & $135.62(13.63)$ & $141.31(13.95)$ & $142.04(14.05)$ & 72 \\
\hline Least performers & & & & & \\
(excl. Control) & & & & $130.54(12.16)$ & 81 \\
$\quad$ - Not exposed & $116.22(13.51)$ & $123.80(11.46)$ & $126.58(11.41)$ & $127.71(22.97)$ & 51 \\
\hline \multicolumn{1}{c}{ Exposed } & $121.25(13.06)$ & $123.47(16.89)$ & $127.39(18.93)$ & & \\
\hline
\end{tabular}

Note: Standard deviations in parentheses.

Table 5. Determinants of the evolution of performance between part 3 and part 4, depending on rank in part 3

\begin{tabular}{|c|c|c|}
\hline $\begin{array}{l}\text { Dependent variable: } \\
\text { Performance in part } 4 \\
\text { - Performance in part } 3\end{array}$ & $\begin{array}{l}\text { Rank } 1 \text { or } 2 \\
\text { in part } 3 \\
\text { (1) }\end{array}$ & $\begin{array}{c}\text { Rank } 3 \\
\text { in part } 3 \\
\text { (2) }\end{array}$ \\
\hline Control treatment & Ref. & Ref. \\
\hline Baseline treatment & $1.794(2.361)$ & $1.934(3.417)$ \\
\hline Homogenous treatment & $0.182(2.250)$ & $-2.364(3.246)$ \\
\hline Heterogeneous treatment & $0.961(2.256)$ & $-1.178(3.150)$ \\
\hline Random treatment & $1.260(2.436)$ & $-2.364(3.411)$ \\
\hline Chose to pay the fee & $-0.512(1.168)$ & $1.161(1.583)$ \\
\hline Exposure of rank 3 in part 3 & $-0.856(1.226)$ & $-3.123 * *(1.472)$ \\
\hline Demographic variables & Yes & Yes \\
\hline Constant & $2.122(5.157)$ & $5.509(7.183)$ \\
\hline $\mathrm{N}$ & 278 & 140 \\
\hline Prob $>F$ & 0.704 & 0.039 \\
\hline $\mathrm{R}^{2}$ & 0.023 & 0.124 \\
\hline
\end{tabular}

Note: $* *$ indicate significance at the $5 \%$ level. 


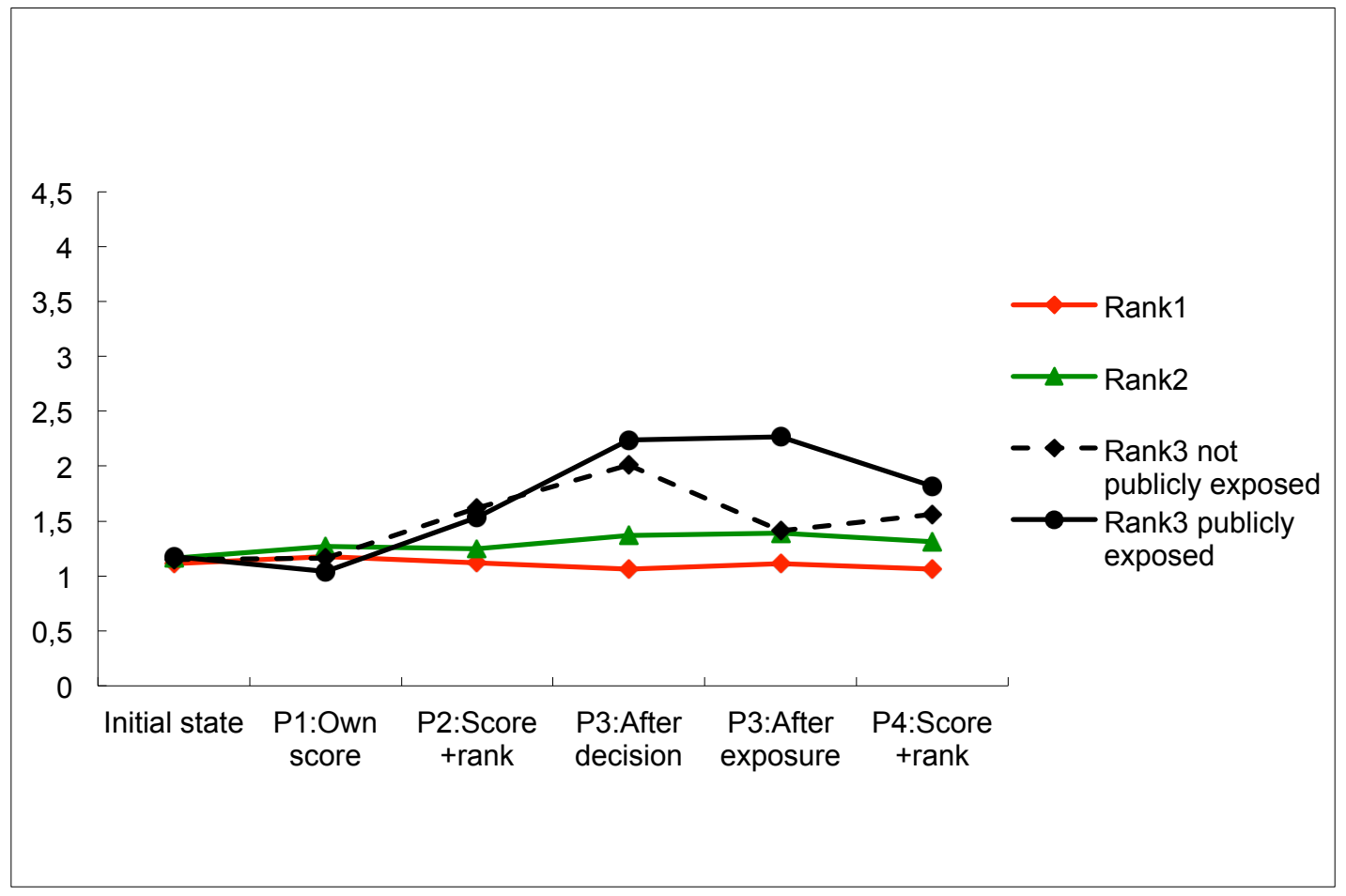

Figure 1. Shame intensity, by performance rank, in all treatments $(\mathrm{N}=396)$

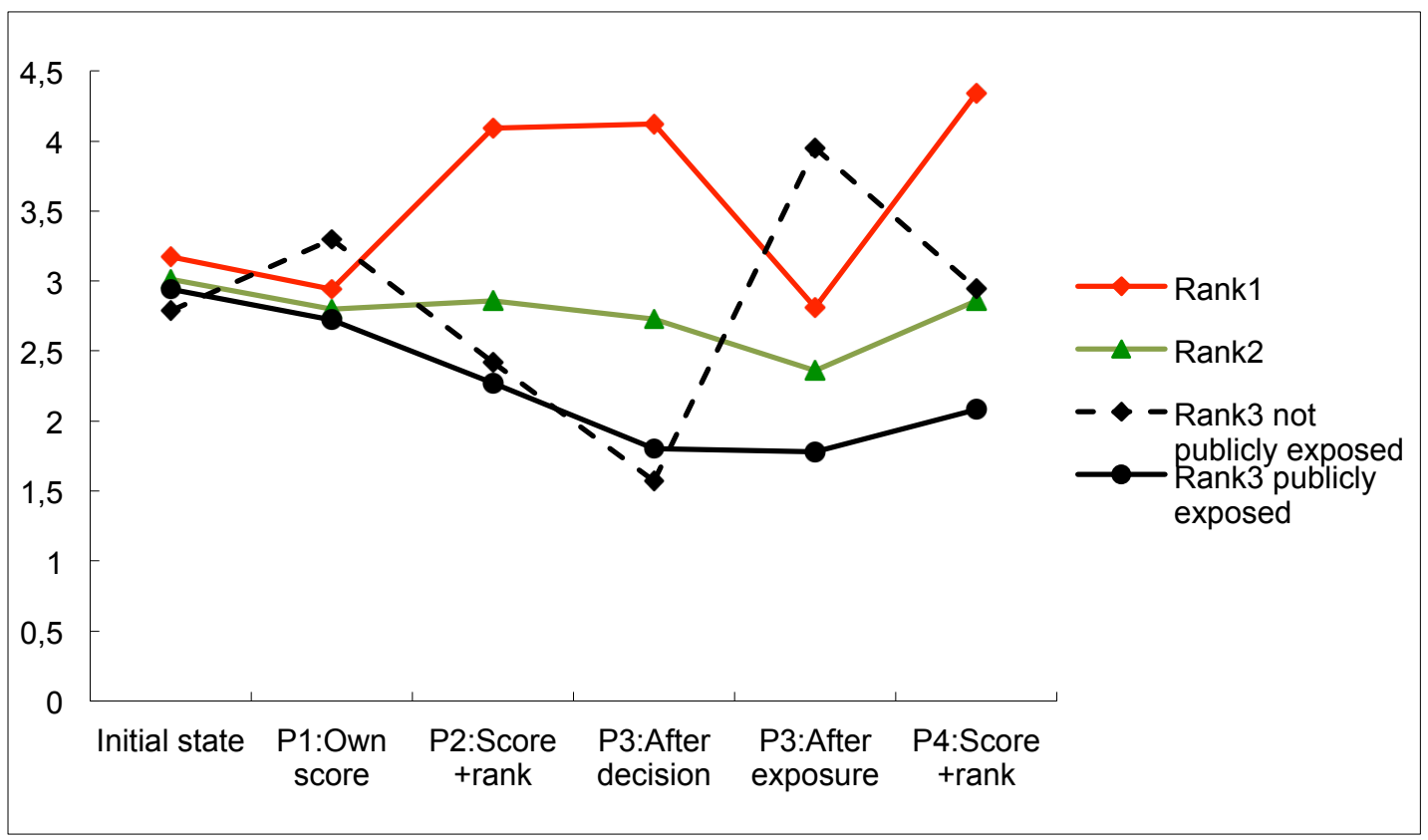

Figure 2. Happiness intensity, by performance rank, in all treatments $(\mathrm{N}=396)$ 


\section{APPENDIX 1 - Instructions for the Baseline treatment (translated into Chinese)}

We thank you for participating in this experiment in decision-making. It is forbidden to talk to the other participants throughout the session.

We will first ask you to describe the feelings you experience right now. Your screen will display a series of 10 statements. For each statement, we ask you to choose a number between 1 and 7 (included) to describe how you feel right now.

The choice of a higher number indicates that you experience this feeling with a higher intensity. For example, choosing number 1 indicates that you do not experience this feeling at all. At the opposite, choosing number 7 indicates that you experience this feeling with a very high intensity. Intermediate values are indicated by the choice of intermediate numbers.

Do not spend too much time on any one statement; simply choose the number which seems to describe your present feelings best.

The 10 proposed statements are the following:

- I feel angry

- I feel contempt

- I feel ashamed

- I feel envious

- $\quad$ I feel sad

- I feel happy

- I feel guilty

- I feel grateful

- I feel fearful

- I feel relieved

\section{Instructions (cont'd) (distributed after completion of the initial elicitation of feelings)}

The remaining of this session consists of several parts. You will receive the instructions for each part after completing the previous part.

During these parts, the amount of money you will earn may depend upon your actions and the actions of the other participants you will interact with. Throughout the session, your earnings will be given in ECU (Experimental Currency Units). At the end of the session, your total earnings in ECU will be the sum of your payoffs earned in each part. These earnings will be converted into RMB at the rate:

$$
10 \mathrm{ECU}=1 \mathrm{RMB}
$$

Your earnings will be paid to you in cash and in private at the end of the session.

\section{Part 1}

At the beginning of this part and throughout the session, the participants are grouped into triads. The composition of your triad will remain constant throughout the session. You will not be informed on the identity of the two other members of your triad.

During this part, we ask you to perform a task on your computer during 4 minutes. This task consists of moving apples into a basket with your mouse.

Each apple moved into the basket will increase your score by one unit. Your current score (i.e. the current number of apples in the basket) as well as the remaining time will be displayed on your screen continuously.

Once the 4 minutes have elapsed, your screen will remind you your score in this part. You will not be informed of the scores of your two other triad members. 
You will be paid $100 \mathrm{ECU}$ in this part.

Before starting performing the task, you will be allowed to practice this task during 2 minutes. The performance in this practice period will not be taken into account in your score of this part.

At the end of this part, a questionnaire about your current feelings will be displayed on your computer screen. To fill out this questionnaire, the rules are the same as previously.

If you have any question regarding these instructions, please raise your hand. We will answer to your questions privately.

\section{Part 2 (distributed after completion of the previous part)}

In this part, the composition of your triad is the same as in the previous part.

We ask you to perform the same task on your computer as previously during 4 minutes. You will be paid 100 ECU in this part.

The difference with the previous part is that once the 4 minutes have elapsed, your screen will display your score and your rank within the triad in this part.

The rank 1 will be assigned to the triad member who has performed the highest score.

The rank 3 will be assigned to the member who has performed the lowest score.

The rank 2 will be assigned to the member who has performed the intermediate score.

In case of ties between two or three triad members, the ranks will be assigned randomly between the ties.

You will be informed of the score and the rank of each of your two other triad members.

Last, a questionnaire about your current feelings will be displayed on your computer screen.

If you have any question regarding these instructions, please raise your hand. We will answer to your questions privately.

\section{Part 3 (distributed after completion of the previous part)}

In this part, the composition of your triad is the same as in the previous parts. We ask you to perform the same task on your computer as previously during 4 minutes. You will be paid $100 \mathrm{ECU}$ in this part. Once the 4 minutes have elapsed, your screen will display your score and your rank within the triad, as well as the score and the rank of each of the two other triad members.

A difference with the previous part lies in the fact that the participants who have got rank 3 (the lowest score) in each triad will be requested to stand up, to move forward to the front of the room, one by one, before being sent back to their seat.

However, you will be able to modify the regular process by your decisions. Indeed, after being informed on the assignment of ranks and before participants with rank 3 (the lowest score) are called to the front of the room, you will decide whether you let the regular process apply or whether you prefer that the member of your triad who has got rank 3 is not called to the front of the room.

- If you are willing that the regular process applies, press «VALIDATE».

- If you are not willing that the member of your triad with rank 3 is called to the front of the room, press «NO STAND UP » and validate your decision.

If at least two members of the triad have pressed «NO STAND UP », the member of your triad who has got rank 3 will not be called and will not be identified in the room. In this case, the members who have chosen « NO STAND UP » will pay a cost of $10 \mathrm{ECU}$ each that will be deducted from their payoff in this part. 
In all the other cases, the regular process applies. The member of your triad with rank 3 will be called to the front of the room. Payoffs will not be modified.

You will be informed of the decision of each of your triad members, together with their score and their rank.

A questionnaire about your current feelings will be displayed on your computer screen both after you have made your decision and after the participants with rank 3 have come back to their seat.

If you have any question regarding these instructions, please raise your hand. We will answer to your questions privately.

\section{Part 4 (distributed after completion of the previous part)}

The rules that apply in this part are the same as in Part 2. We ask you to perform the same task as previously during 4 minutes. You will be paid $100 \mathrm{ECU}$ in this part. Once the 4 minutes have elapsed, your screen will display your score and your rank within the triad in this part. You will be also informed of the score and the rank of each of the two other triad members. Then, a questionnaire about your current feelings will be displayed on your computer screen.

Finally, you will be requested to fill out a post-experimental questionnaire and you will be invited to proceed to the payment room. 


\section{APPENDIX 2 - Instructions for the Homogenous and Heterogeneous treatments (translated into Chinese)}

We thank you for participating in this experiment in decision-making. It is forbidden to talk to the other participants throughout the session.

We will first ask you to describe the feelings you experience right now. Your screen will display a series of 10 statements. For each statement, we ask you to choose one number between 1 and 7 (included) to describe how you feel right now.

The choice of a higher number indicates that you experience this feeling with a higher intensity. For example, choosing number 1 indicates that you do not experience this feeling at all. At the opposite, choosing number 7 indicates that you experience this feeling with a very high intensity. Intermediate values are indicated by the choice of intermediate numbers.

Do not spend too much time on any one statement; simply choose the number which seems to describe your present feelings best.

The 10 proposed statements are the following:

- I feel angry

- I feel contempt

- I feel ashamed

- I feel envious

- I feel sad

- I feel happy

- I feel guilty

- I feel grateful

- I feel fearful

- I feel relieved

\section{Instructions (cont'd) (distributed after completion of the initial elicitation of feelings)}

The remaining of this session consists of several parts. You will receive the instructions for each part after completing the previous part.

During these parts, the amount of money you will earn may depend upon your actions and the actions of the other participants you will interact with. Throughout the session, your earnings will be given in ECU (Experimental Currency Units). At the end of the session, your total earnings in ECU will be the sum of your payoffs earned in each part. These earnings will be converted into RMB at the rate:

$$
10 \mathrm{ECU}=1 \mathrm{RMB}
$$

Your earnings will be paid to you in cash and in private at the end of the session.

\section{Preliminary part}

At the beginning of this part and for the remainder of the session, the participants will be classified into one of two groups of equal size. Each group is called after the name of an artist: Klee or Kandinsky. You will be randomly assigned to one of these two groups, either the Klee group, or the Kandinsky group. You will belong to the same group throughout the session.

After informing you about your group membership, your screen will display five pairs of paintings. In each pair, a painting has been made by Klee, the other one by Kandinsky. Your screen will indicate which artist has painted each painting. Each pair of paintings will be displayed during 20 seconds.

After observing these five pairs of paintings, your screen will successively display two more paintings and you will be asked to select the artist who you think made each painting, respectively (Klee or Kandinsky). Each correct answer will pay you 50 ECU. 
You may get help from or help other members in your own group while answering the two questions successively. Indeed, before submitting each of your answers, you can use a group chat program during 3 minutes to get help from or offer help to other members in your own group.

Except for the following restrictions, you can type whatever you want in the lower box of the chat program:

- Please do not identify yourself or send any information that could be used to identify you (age, gender, school, ...),

- Please refrain from using obscene or offensive language.

To send a message to your group members, simply press the $d$ button.

Your messages will be shared only with the members of your own group. You will not be able to see the messages exchanged among the other group. People in the other group will not see the messages from your own group either.

Once the communication time has elapsed, you will be requested to enter your answer about the artist you think has made the painting displayed on your screen (Klee or Kandinsky).

You will be informed at the end of the session whether your answers were correct or not.

Once you have submitted your two answers, a questionnaire on your current feelings will be displayed on your computer screen. To fill out this questionnaire, the rules are the same as previously.

Please read these instructions again. If you have any question on these instructions, please raise your hand. We will answer your questions privately.

\section{Part 1}

At the beginning of this part and throughout the session, the participants are grouped into triads. The composition of your triad will remain constant throughout the session. You will not be informed on the identity of the other members of your triad. In contrast, you will be informed of the group of each of the two other triad members (Klee or Kandinsky); similarly, your triad members will learn your group.

During this part, we ask you to perform a task on your computer during 4 minutes. This task consists of moving apples into a basket with your mouse.

Each apple moved into the basket will increase your score by one unit. Your current score (i.e. the current number of apples in the basket) as well as the remaining time will be displayed on your screen continuously.

Once the 4 minutes have elapsed, your screen will remind you your score in this part. You will not be informed of the scores of your two other triad members.

You will be paid $100 \mathrm{ECU}$ in this part.

Before starting performing the task, you will be allowed to practice this task during 2 minutes. The performance in this practice period will not be taken into account in your score of this part.

At the end of this part, a questionnaire about your current feelings will be displayed on your computer screen.

If you have any question regarding these instructions, please raise your hand. We will answer to your questions privately.

\section{Part 2 (distributed after completion of the previous part)}

In this part, the composition of your triad is the same as in the previous part. We ask you to perform the same task on your computer as previously during 4 minutes. You will be paid $100 \mathrm{ECU}$ in this part.

The difference with the previous part is that once the 4 minutes have elapsed, your screen will display your score and your rank within the triad in this part.

The rank 1 will be assigned to the triad member who has performed the highest score. 
The rank 3 will be assigned to the member who has performed the lowest score.

The rank 2 will be assigned to the member who has performed the intermediate score.

In case of ties between two or three triad members, the ranks will be assigned randomly between the ties.

You will be informed of the group (Klee or Kandinsky), the score and the rank of each of your two other triad members. Last, a questionnaire about your current feelings will be displayed on your computer screen.

If you have any question regarding these instructions, please raise your hand. We will answer to your questions privately.

\section{Part 3 (distributed after completion of the previous part)}

In this part, the composition of your triad is the same as in the previous parts. We ask you to perform the same task on your computer as previously during 4 minutes. You will be paid $100 \mathrm{ECU}$ in this part.

Once the 4 minutes have elapsed, your screen will display your score and your rank within the triad, as well as the group (Klee or Kandinsky), the score and the rank of each of the two other triad members.

A difference with the previous part lies in the fact that the participants who have got rank 3 (the lowest score) in each triad will be requested to stand up, to move forward to the front of the room, one by one, and then to give the name of their group (Klee or Kandinsky) aloud before being sent back to their seat.

However, you will be able to modify the regular process by your decisions. Indeed, after being informed on the assignment of ranks and before participants with rank 3 (the lowest score) are called to the front of the room, you will decide whether you let the regular process apply or whether you prefer that the member of your triad who has got rank 3 is not called to the front of the room.

- If you are willing that the regular process applies, press «VALIDATE».

- If you are not willing that the member of your triad with rank 3 is called to the front of the room, press «NO STAND UP » and validate your decision.

If at least two members of the triad have pressed «NO STAND UP », the member of your triad who has got rank 3 will not be called and will not be identified in the room. In this case, the members who have chosen « NO STAND UP » will pay a cost of $10 \mathrm{ECU}$ each that will be deducted from their payoff in this part.

In all the other cases, the regular process applies. The member of your triad with rank 3 will be called to the front of the room, will give the name of his group aloud and will come back to his seat. Payoffs will not be modified.

You will be informed of the decision of each of your triad members, together with their group, their score and their rank.

A questionnaire about your feelings will be displayed on your computer screen both after you have made your decision and after the participants with rank 3 have come back to their seat.

If you have any question regarding these instructions, please raise your hand. We will answer to your questions privately.

\section{Part 4 (distributed after completion of the previous part)}

The rules that apply in this part are the same as in part 2 . We ask you to perform the same task as previously during 4 minutes. You will be paid $100 \mathrm{ECU}$ in this part.

Once the 4 minutes have elapsed, your screen will display your score and your rank within the triad in this part. You will be also informed of the group (Klee or Kandinsky), the score and the rank of each of the two other triad members. Then, a questionnaire about your current feelings will be displayed on your computer screen.

Finally, you will be requested to fill out a post-experimental questionnaire and you will be invited to proceed to the payment room. 